\title{
Da certificação para as concessões florestais: organizações não governamentais, empresas e a construção de um novo quadro institucional para o desenvolvimento da exploração florestal na Amazônia brasileira \\ On the certification of forest concession: non-governmental organizations, enterprises, and the construction of a new institutional frame for the development of the lumber industry in the Brazilian Amazon
}

\author{
Marcelo Sampaio Carneiro \\ Universidade Federal do Maranhão. São Luís, Maranhão, Brasil
}

\begin{abstract}
Resumo: $\bigcirc$ artigo discute o processo de construção da certificação florestal na Amazônia brasileira, destacando sua importância para a construção de um novo quadro de suporte à produção madeireira nessa região. Nele, sustentamos que um dos principais resultados da promoção da certificação florestal do Forest Stewardship Council (FSC) na Amazônia foi a constituição de uma aliança entre representantes de organizações não governamentais, ecologistas, segmentos do empresariado florestal e membros da burocracia estatal para a promoção da exploração madeireira baseada no manejo florestal. Nessa perspectiva, os resultados produzidos pela certificação devem ser compreendidos como parte de um processo de promoção das políticas de acesso ao recurso florestal, como são os casos da aprovação da Lei de Gestão das Florestas Públicas e da criação de organizações estatais destinadas ao fomento da produção madeireira na Amazônia.
\end{abstract}

Palavras-chave: Indústria madeireira. Organizações não governamentais. Certificação florestal. Amazônia. Manejo florestal. Políticas públicas.

\begin{abstract}
The article discusses the construction process of forest certification in the Brazilian Amazon, emphasizing its importance for the new frame of lumber industry on that region. We sustain that one of the main results of the promotion of forest certification by the Forest Stewardship Council (FSC) in Amazon was the constitution of an alliance between the environmentalist Non-Governmental Organizations, representative segments of forest business and members of the state bureaucracy for the promotion of lumber exploration based on forest management. In this perspective, the results produced by certification must be understood as part of a process of promotion of forest resources access policies, such as the approval of the Public Forests Management Law, and the creation of state entities destined to the promotion of lumber extraction on Amazon.
\end{abstract}

Keywords: Lumber industry. Non-Governmental Organizations. Forest certification. Amazon. Forest management. Public policies.

CARNEIRO, Marcelo Sampaio. Da certificação para as concessões florestais: organizações não governamentais, empresas e a construção de um novo quadro institucional para o desenvolvimento da exploração florestal na Amazônia brasileira. Boletim do Museu Paraense Emílio Goeldi. Ciências Humanas, v. 6, n. 3, p. 525-541, set.-dez. 2011.

Autor para correspondência: Marcelo Sampaio Carneiro. Condomínio Villaggio Jardins 2, casa 21. Rua das Orquídeas. Jardim SM I. Cohama. São Luis, MA, Brasil. CEP 65072-561 (marcelodsc@ufma.br).

Recebido em 14/07/2010

Aprovado em 20/09/2011

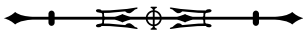




\section{INTRODUÇÃO}

Este artigo discute o processo de construção da certificação florestal na Amazônia brasileira, destacando a importância desse processo para um novo quadro de suporte à produção madeireira na região, isto é, procurando realçar as principais mudanças institucionais que ocorreram após o desenvolvimento das ações de promoção da produção florestal certificada.

O argumento que sustenta essa análise defende a tese de que um dos principais resultados da promoção da certificação florestal do Forest Stewardship Council (FSC) na Amazônia foi a constituição de uma aliança entre seus principais defensores: as organizações não governamentais (ONGs) (Instituto do Homem e Meio Ambiente da Amazônia - IMAZON, Greenpeace, World Wildlife Fund - WWF-Brasil, Amigos da Terra e Instituto de Manejo e Certificação Florestal e Agrícola - IMAFLORA), um grupo específico de empresários florestais e integrantes da burocracia estatal situados em órgãos ambientais federais e estaduais.

Será a aliança entre os representantes das ONGs, empresas e instituições governamentais que permitirá o desenvolvimento de iniciativas centrais para a modificação do quadro institucional ${ }^{1}$ da produção madeireira regional, isto é, a constituição de centros para a difusão da tecnologia da exploração florestal de impacto reduzido, esforços para a promoção da comercialização dos produtos certificados e o estabelecimento de mecanismos de financiamento apropriados à atividade econômica florestal (Carneiro, 2004; 2007).

Destacar o papel da certificação florestal na mudança do padrão de funcionamento de parcela da indústria florestal na Amazônia tem um significado importante, pois contesta o argumento de vários autores de que aquele instrumento seria incapaz de promover mudanças substantivas na atividade florestal. Para esses autores, a certificação apenas reforçaria o poder de algumas ONGs transnacionais (Smouts, 2001) e favoreceria um número reduzido de empresas (Thornber et al., 2000; Laschefski, 2003; Nepstad et al., 2005).

O artigo está organizado em quatro seções: na primeira parte, apresentamos algumas ações de ONGs ambientalistas no processo de promoção da certificação florestal na Amazônia; por meio dessa descrição, procuramos destacar o protagonismo das ONGs na viabilização da certificação.

$\mathrm{Na}$ segunda seção, analisamos o comportamento da principal entidade de representação do empresariado florestal da Amazônia quando confrontada com a proposta da certificação. Por meio da análise do comportamento da Associação das Indústrias Exportadoras de Madeira do Estado do Pará (AIMEX), procuramos mostrar como um segmento do empresariado florestal, representado por essa entidade, passou de uma forte oposição à proposta e aderiu à certificação florestal.

$\mathrm{Na}$ terceira seção, apresentamos a evolução das operações certificadas na Amazônia, isto é, realizamos um inventário das empresas ou comunidades que tiveram suas operações florestais certificadas, associando elementos da dinâmica política regional a essa evolução, com o intuito de mostrar como determinadas ações governamentais (relacionadas com a operacionalização da Lei de Gestão de Florestas Públicas) condicionam o crescimento ou não das áreas certificadas. Apesar de mencionarmos as operações de manejo florestal comunitário certificadas, o foco do nosso estudo é o manejo florestal de larga escala realizado por empresas florestais, de forma que não abordaremos as questões e

\footnotetext{
Estamos nos referindo ao quadro institucional em sentido semelhante ao definido por Costa (2007), ou seja, como ambiente institucional. Segundo esse autor, para a promoção de um desenvolvimento em termos sustentáveis na Amazônia, faz-se necessária "a reconstrução da institucionalidade que medeia a relação do Estado com as sociedade regionais, i.e., [que] implica a alteração dos nexos objetivos que articulam organizações e visões de mundo, estruturas organizacionais e posturas individuais nessa mediação" (Costa, 2007, p. 152).
}

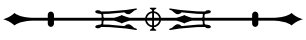


os problemas associados à certificação do manejo florestal comunitário na Amazônia (Lima et al., 2009).

Na última parte do texto, realizamos um balanço das principais mudanças que identificamos com a ação dos proponentes da certificação na Amazônia. Nela, destacamos o apoio dado para o crescimento das empresas florestais certificadas e a promoção de um conjunto de mudanças nas condições estruturais de acesso ao recurso florestal, caso da aprovação da Lei de Gestão das Florestas Públicas; destacamos também a criação de organizações estatais destinadas ao fomento da produção madeireira na Amazônia, caso do Serviço Florestal Brasileiro (SFB) e de instituições semelhantes no plano estadual, como o Instituto de Desenvolvimento Florestal do Estado do Pará (IDEFLOR).

\section{A ATUAÇÃO DAS ONGS AMBIENTALISTAS}

Nesta seção, expomos o papel desempenhado por um grupo específico de ONGs ambientalistas (Buclet, 2002; Carneiro, 2004) na promoção do mercado para madeiras certificadas, oriundas de florestas nativas da Amazônia brasileira. Conforme nossa interpretação, a partir das iniciativas lideradas por essas ONGs, atuando em faixas específicas de sua competência, serão lançadas as bases para o fomento da certificação.

Nesse processo, destacamos duas dimensões que nos parecem essenciais: i) o trabalho de crítica ao padrão tradicional da exploração florestal, realizado por meio de diversos mecanismos, mas com especial destaque para as pressões efetuadas por ONGs ambientalistas na cadeia global do comércio de madeiras, as quais estimulam a adoção da certificação das empresas na Amazônia; e ii) a atuação na construção de instrumentos para a oferta e o consumo de madeira certificada, por meio da criação do grupo de compradores de produtos florestais certificados e da difusão da tecnologia da exploração florestal de baixo impacto ${ }^{2}$.

\section{A PRESSÃO PARA A CERTIFICAÇÃO DAS EMPRESAS E O CONTROLE INTERNO DO SISTEMA FSC: A ATUAÇÃO DO GREENPEACE}

O Greenpeace participa de diversas formas no processo de desenvolvimento do FSC na Amazônia. O aspecto mais evidente dessa contribuição é o envolvimento da ONG na constituição do Grupo de Trabalho do FSCBrasil e no seu funcionamento posterior. Contudo, acreditamos que o elemento mais importante dessa atuação está centrado em dois outros tipos de atividades realizadas pelo grupo ecologista: a) no trabalho de denúncia e combate da atividade madeireira ilegal e/ ou predatória; e b) na construção de credibilidade do sistema de certificação do FSC e no combate a sistemas de certificação concorrentes.

No primeiro caso, a entidade desempenha o papel de crítica [voice, na terminologia de Hirschman (1973)] ao funcionamento do mercado de madeiras tropicais, por intermédio das atividades realizadas no âmbito de sua campanha pela proteção das florestas primárias. Por meio dessa campanha, o Greenpeace desenvolve diversos tipos de mobilização no Brasil e no exterior publica relatórios sobre a situação da floresta amazônica; promove movimentos de boicote à compra de produtos oriundos dessa fonte; realiza ações diretas, chamando atenção para o problema; interpela judicialmente os atores da exploração ilegal etc. Do ponto de vista da promoção do mercado de madeiras certificadas, essa atuação apresenta um duplo efeito: ela torna mais cara a permanência de empresas atuando ilegalmente no mercado de madeiras, estimulando, ao mesmo tempo, outras empresas a procurarem alternativas à ilegalidade ou má gestão da exploração florestal.

O Greenpeace indica 1992 como o ano de início do seu trabalho de "investigação da exploração ilegal e predatória de madeira na Amazônia brasileira"

\footnotetext{
2 Essas seções condensam informações apresentadas em outro artigo (Carneiro, 2007) e apresentam novos dados sobre a atuação das ONGs envolvidas na promoção da certificação florestal.
}

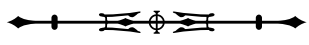


(Greenpeace Brasil, 2003, p. 4). Contudo, foi em 1994 que os principais relatórios ${ }^{3}$ da campanha pela proteção das florestas primárias do grupo foram lançados, tanto no Brasil ("À margem da lei" e "Imagens da destruição") como no mundo ("Comprando a destruição" e "Alternativas comerciais à destruição de florestas primárias"), todos centrados na denúncia da indústria madeireira como a principal vilã desse processo de destruição e apontando algumas alternativas para contê-lo.

Em linhas gerais, a estratégia proposta pelo grupo implica a sensibilização de grandes consumidores de produtos florestais, de governos (em suas diferentes esferas) e de empresas madeireiras para a necessidade da adoção do manejo ecologicamente sustentável das florestas primárias, de acordo com o proposto pela certificação do FSC; da criação de unidades de conservação para a proteção dessas florestas; do encorajamento ao lançamento de produtos ecológicos alternativos; e da promoção de um uso mais eficaz dos produtos madeireiros oriundos de florestas primárias (Greenpeace International, 1999b, p. 12-13).

Para o caso específico da floresta amazônica, o Greenpeace sugeriu, após ressaltar o peso crescente de empresas florestais na produção brasileira de madeiras tropicais, a adoção de algumas medidas, tais como: a interdição da autorização de novas concessões para exploração florestal em áreas de florestas primárias; a certificação, através do FSC, das operações florestais das empresas já em atividade nessas áreas; a suspensão parcial das atividades de empresas com concessões ainda inexploradas; a necessidade da realização de um inventário sobre o setor florestal na região (a ser realizado pelo governo brasileiro); e o consumo de produtos florestais certificados pelo FSC (Greenpeace International, 1999a, p. 12).

Normalmente, esses relatórios representam o primeiro momento de uma campanha mais ampla, que envolve, nos momentos seguintes, a realização de alguma ação direta, a midiatização da campanha e a apresentação de alguma petição sobre o alvo focalizado. Esse foi o caso do grupo francês Lapeyre, que teve atuação na Amazônia - por meio de uma subsidiária, a empresa Eldorado Exportação e Serviços - criticada por campanha do Greenpeace. Ao final desta ação, o grupo francês assumiu o compromisso de, num prazo de quatro anos, se abastecer somente de madeira certificada e orientou sua subsidiária a participar do Grupo de Compradores de Madeira Certificada no Brasil.

Quanto ao segundo papel cumprido pela ONG, que diz respeito à construção da credibilidade do selo do FSC na região, podemos dizer que ele se desenvolve em dois fronts, no campo interno do sistema de certificação FSC, por meio do acompanhamento dos processos de certificação em curso e da intervenção em casos nos quais pairem dúvidas sobre o mérito da avaliação realizada (Carneiro, 2004), e no campo externo, pelo combate à implantação de sistemas de certificação concorrentes do FSC, caso do Programa Brasileiro de Certificação Florestal (CERFLOR), e do proselitismo das vantagens do FSC (Greenpeace Brasil, 2002).

A preocupação com a legitimidade do sistema FSC no Brasil e a disputa de credibilidade com outras iniciativas de construção de um selo florestal são questões centrais para a atuação do Greenpeace, que serão abordadas a partir da análise do relatório "CERFLOR: empresas e governo têm credibilidade para realizar certificação florestal?". Produzido com o objetivo de comparar os sistemas de certificação florestal existentes no Brasil, o relatório representa uma peça de defesa das vantagens do sistema de certificação do FSC frente ao CERFLOR, iniciativa de segmentos do patronato florestal e do governo brasileiro. As principais vantagens apontadas pelo relatório são duas: maior

\footnotetext{
A publicação dos relatórios possui diversas finalidades: possibilita ao Greenpeace firmar, junto a certos segmentos da sociedade civil, uma dada percepção sobre a situação da utilização dos recursos florestais na Amazônia; justifica a atuação do grupo, que, dessa forma, estaria cumprindo seu papel de militante coletivo, lutando contra a destruição desses recursos naturais, permitindo-lhe, ainda, tornar públicas determinadas petições às empresas do setor florestal, ao governo e às empresas consumidoras de madeira.
}

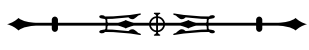


participação de representantes de ONGs e movimentos sociais na elaboração dos padrões e da estrutura de gestão do FSC, e menor transparência do processo de certificação do CERFLOR, que "não especifica a necessidade de consultas públicas, determina confidencialidade total dos resultados das auditorias e condiciona qualquer divulgação à aprovação do auditado" (Greenpeace Brasil, 2002, p. 26).

Independentemente da avaliação que possa ser feita do seu conteúdo, a publicação do relatório serviu para mostrar que a implantação do CERFLOR ${ }^{4}$ representou um desafio a mais para o processo de desenvolvimento do FSC no Brasil, reafirmando, ao mesmo tempo, o papel desempenhado pelo Greenpeace na promoção desse selo como o dispositivo de certificação mais apropriado para a proteção das florestas tropicais, de forma semelhante ao que vem ocorrendo em outras situações na Europa e na Ásia (Smouts, 2001).

\section{CONSTRUINDO A DEMANDA E A OFERTA} PARA A MADEIRA CERTIFICADA: A FORMAÇÃO DO GRUPO DE COMPRADORES E A DIFUSÃO DA TECNOLOGIA FLORESTAL PARA A

\section{EXPLORAÇÃO DE IMPACTO REDUZIDO}

$\bigcirc$ grupo de compradores de madeira certificada ${ }^{5}$, seção brasileira da Rede Global de Comércio e Floresta, foi fundado em abril de 2000, contando originalmente com 38 membros. Como será demonstrado em seguida, sua constituição foi resultado da atuação de três ONGs: IMAFLORA, IMAZON e Amigos da Terra - Programa Amazônia, por intermédio da parceria denominada "Aliança para o consumo sustentável", cabendo a esta última um papel mais direto na condução do grupo.

A necessidade do desenvolvimento de iniciativas para tentar organizar uma atuação no mercado interno de madeiras no Brasil é uma preocupação que antecede a criação do grupo de compradores. Destarte, já em 1997, no trabalho "Garimpagem Florestal: relatório atualizado sobre a extração ilegal de madeira na Amazônia brasileira", a ONG Amigos da Terra esboçou um programa de atuação nesse sentido, de forma a investir na construção do mercado para a produção florestal certificada (Amigos da Terra, 1997, p. 19).

Em 1998, o IMAFLORA firmou parceria com Amigos da Terra e deu novo formato ao seu Programa de Apoio à Comercialização de Produtos Certificados, passando a trabalhar junto a setores produtivos: enquanto à outra ONG coube as "atividades relacionadas com a divulgação junto aos consumidores finais" (IMAFLORA, 2000, p. 56). Além dessa nova divisão de trabalho, a entidade decidiu realizar um estudo detalhado do funcionamento do mercado de madeira na região centro-sul do Brasil, agregando para tanto o IMAZON, ONG que dispunha de savoir-faire mais adequado à realização desse trabalho.

Assim, foram publicados pelas ONGs da "Aliança para o consumo sustentável" dois estudos sobre o potencial do mercado consumidor brasileiro para produtos certificados. Como parte desse esforço, foram publicados os estudos "Acertando o Alvo" (Smeraldi e Veríssimo, 1999) e "Acertando o Alvo 2" (Sobral et al., 2002). Por intermédio desses trabalhos, procura-se reforçar a tese da possibilidade da venda de produtos certificados no mercado interno brasileiro, ponto sobre o qual a introdução ao trabalho é incisiva:

\begin{abstract}
Existe o mito de que o mercado brasileiro de madeiras amazônicas não tem interesse em adquirir produtos florestais certificados. Este levantamento inédito realizado em 2001 no estado de São Paulo (...) revela uma situação surpreendente: há uma demanda para madeira certificada de aproximadamente $20 \%$ (1,2 milhão de metros cúbicos em tora) do volume total consumido no estado (Sobral et al., 2002, p. 7).
\end{abstract}

Outra iniciativa importante dessas entidades tem sido a organização das Feiras de Produtos Florestais Certificados

\footnotetext{
4 Até o fim de 2010, o CERFLOR certificou um total de 1,47 milhões de hectares, contudo, todos os empreendimentos certificados correspondem a florestas plantadas e localizam-se fora da Amazônia (Pereira et al., 2010, p. 86).

5 Posteriormente, a entidade teve seu nome alterado para Grupo de Comparadores de Produtos Florestais Certificados. Como o principal de sua atuação está voltado para a promoção do mercado de madeiras, continuaremos utilizando sua denominação original ao longo do trabalho.
}

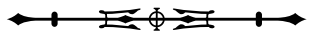


(Mantelatto et al., 2008), que são realizadas bianualmente, desde 2004, na cidade de São Paulo. A realização dessas feiras cumpre diversas funções: possibilitam o encontro entre produtores e consumidores de produtos florestais certificados, permitem que a promoção da certificação ocupe um importante espaço na imprensa nacional e se constituem em espaços de discussão dos principais entraves ao avanço da certificação, aproveitando o fato de convergirem para esses eventos representantes do poder público, de empresários e de ONGs e movimentos sociais.

Como alguns experts florestais destacaram (Hinrichs e Ruslim, 2001; Dykstra, 2001), um dos principais entraves ao desenvolvimento da exploração de impacto reduzido $(E I R)^{6}$ tem sido a dificuldade para fazer com que essa tecnologia seja incorporada pelas empresas do setor florestal. No caso da Amazônia brasileira, essa deficiência começou a ser superada a partir do início dos anos 1990, com a difusão das tecnologias de EIR pelo IMAZON.

Embora essa atuação do IMAZON tenha sido importante, ela apresentava limitações evidentes, visto que a adoção pelas empresas das indicações geradas pelas pesquisas - realizadas em grande parte por instituições públicas ${ }^{7}$, como a Empresa Brasileira de Pesquisa Agropecuária (EMBRAPA), o Instituto Nacional de Pesquisas da Amazônia (INPA) e a Universidade Federal Rural da Amazônia (UFRA) (Silva et al., 1996) - demandaria um esforço mais consistente. Seria o caso de um programa de formação de profissionais do setor florestal, tarefa que foi assumida e executada pelo Instituto Floresta Tropical (IFT) ${ }^{8}$.

O IFT começou a operar na Amazônia em 1994, trabalhando a partir de uma base de pesquisa e treinamento estabelecida em Paragominas, em uma área de um mil hectares cedida pela empresa Cikel Brasil Verde S/A, a partir da qual a entidade realiza a "promoção e a disseminação do manejo sustentável das florestas tropicais", com uma ênfase especial "na implantação de modelos de manejo florestal e exploração de impacto reduzido", junto a produtores, instituições governamentais e não governamentais do setor florestal (FFT, 2000).

A estratégia de difusão da tecnologia de exploração de impacto reduzido do IFT inclui um variado leque de instrumentos: os cursos já citados e que são realizados nas áreas da Fundação; treinamentos in situ, com a demonstração da tecnologia da EIR diretamente nas áreas das empresas; estágios para estudantes de nível médio e superior; dias de campo, instrumento tradicional da prática extensionista para processos de transferência de tecnologia; além de incluir a elaboração e divulgação de publicações e vídeos sobre o tema.

Embora todas essas atividades desenvolvidas pelo IFT estejam intimamente relacionadas com o fomento da certificação, uma merece destaque especial, o treinamento in situ - realizado diretamente nas áreas das empresas interessadas -, uma vez que três das quatro empresas que tiveram esse tipo de treinamento obtiveram a certificação do FSC: a Gethal, a Cikel e a Juruá (FFT, 2001, p. 7). Essa relação entre o trabalho do IFT e a certificação florestal é destacada em artigo que faz um balanço da atuação da entidade:

Ao longo de sua existência, o IFT pôde também
contribuir com a implantação da certificação florestal
FSC na Amazônia brasileira, por meio de inúmeras
parcerias com entidades e empresas florestais,
objetivando sempre o apoio à implantação e
manutenção de áreas florestais bem manejadas.
Participou, ainda, da construção e implantação

\footnotetext{
6 Bull et al. (2001, p. 12), após análise de cerca de 270 publicações tratando do tema, chegaram à seguinte definição: "A EIR é a execução intensamente planejada e atentamente controlada das operações de colheita florestal com vistas à redução ao mínimo do impacto sobre os povoamentos e os solos florestais, quando do corte seletivo de árvores individuais".

7 No caso específico das empresas Cikel Brasil Verde e Juruá Florestal, a EMBRAPA atuou na transferência de tecnologia por meio do projeto "Bom Manejo: manejo sustentável de florestas na Amazônia brasileira" (Carneiro, 2004, p. 215).

8 A Fundação Floresta Tropical, ONG com sede em Belém, fundada em 1994, surgiu como decorrência das pesquisas sobre exploração de impacto reduzido realizadas na Amazônia Oriental pela entidade norte-americana Tropical Forest Foundation, em parceria com o IMAZON. Posteriormente, a Fundação teve o nome modificado e passou a chamar-se Instituto Floresta Tropical.
}

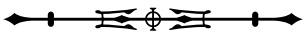


dos padrões de certificação FSC (...). Além disso, colaborou na formação de auditores florestais, com a realização de eventos de capacitação para esse grupo de profissionais (Couto e Roncoletta, 2008, p. 218).

\section{AS EMPRESAS DO SETOR FLORESTAL FACE AO DESAFIO DA CERTIFICAÇÃO: A EVOLUÇÃO DO POSICIONAMENTO DA AIMEX}

A representação institucional do setor madeireiro amazônico é diversificada, sendo realizada no formato tradicional do sindicalismo empresarial brasileiro (Confederação Federação - Sindicatos) ou por estruturas de mobilização mais flexíveis, adaptadas ao grau de informalidade e às características extrativas que marcam uma importante parcela do setor. No interior desse conjunto de entidades, uma se destaca não tanto pela abrangência da sua área de atuação, mas pelo peso econômico de suas representadas no conjunto do setor e pelo forte ativismo que marca sua atuação: a AIMEX (Sember, 1999).

Uma das marcas desse ativismo tem sido o combate à atuação de grandes ONGs ambientalistas internacionais, mais especificamente o Greenpeace, na Amazônia. Essa reiterada manifestação da AIMEX contra o que considera uma intervenção externa e equivocada nos problemas amazônicos encontra eco no conjunto dos empresários do setor, pois, como mostrou uma pesquisa de opinião realizada pelo Instituto de Estudos da Religião (ISER) para o WWF, uma das maiores preocupações desse segmento refere-se à imagem que possuem de "predadores do meio ambiente na Amazônia", representação essa que seria fruto da ação do governo, da imprensa e dos ecologistas (MWF-Brasil, 2001).

Em alguns casos, essa percepção dos empresários do setor levou à identificação da certificação como mais uma manifestação do 'ecolonialismo' das ONGs do hemisfério norte, como pode ser observado na descrição feita por Samuel Benchimol (1998), tomado aqui como porta-voz do empresariado tradicional do setor madeireiro, da inviabilidade da atividade de manejo florestal da empresa Precious Wood Amazon (PWA), a primeira a receber o selo do FSC na Amazônia. Falando das adversidades enfrentadas pelo setor madeireiro no estado do Amazonas e das dificuldades em conciliar a exploração florestal com a proteção do meio ambiente, ele argumentou que esse empreendimento, saudado como modelo por ONGs e ambientalistas, era subsidiado por fundos de pensão suíços e que não visava lucro, não tendo, portanto, viabilidade econômica efetiva (Benchimol, 1998, p. 115).

Argumentação semelhante pode ser encontrada no depoimento prestado pelo empresário Ovídio Gasparetto, ex-presidente da AIMEX, em intervenção realizada no Seminário "Amazônia Século XXI - Perspectivas para - Desenvolvimento", promovido pela Câmara dos Deputados, na qual ele reclama do atraso na construção de um selo por parte do setor florestal da Amazônia:

\begin{abstract}
Por comodismo ou qualquer outro motivo, negligenciamos a importância desse documento, hoje um passaporte internacional para a comercialização e a comprovação da sustentabilidade das madeiras, e hoje somos reféns de uma única companhia certificadora internacional, o Forest Stewardship Council - FSC, da qual faz parte o Greenpeace ${ }^{9}$.
\end{abstract}

Essa apreciação negativa quanto à certificação florestal promovida pelas ONGs ambientalistas não impediu a AIMEX de atuar de forma extremamente pragmática em relação ao FSC, participando de sua constituição (Faillace, 1996) e dos debates que se seguiram para a elaboração dos padrões de certificação em florestas naturais de terra firme.

Nessa trajetória de participação da AIMEX nas discussões sobre a certificação, dois momentos devem ser destacados, pois implicaram a ameaça da entidade de se retirar do FSC. O primeiro desses momentos ocorreu em 1998, em razão de uma divergência sobre o processo de elaboração da norma de certificação para o manejo em floresta de terra firme na Amazônia (Boletim semanal...,

\footnotetext{
9 Notas taquigráficas do Seminário Amazônia..., Câmara dos Deputados, 28/03/2001, p. 108.
} 
1998); e o segundo, no ano 2000, com a reclamação da AIMEX de que estaria ocorrendo uma nova rodada de imposições de ONGs, dessa vez "com marcante perfil sindical e ideológico", as quais estariam exigindo que a certificação fosse estendida a todas as fontes de suprimento de uma determinada empresa e não somente à unidade de manejo em certificação, exigindo também que os documentos da auditoria de certificação fossem colocados à disposição das ONGs e não somente da empresa certificadora (Boletim semanal..., 2000a).

Contudo, o que merece maior destaque nesses episódios é o contato, realizado em 1998, da AIMEX com a Associação Brasileira de Normas Técnicas (ABNT) para a elaboração de outros princípios e critérios, o que virá a se concretizar na elaboração do selo florestal do CERFLOR, iniciativa do Ministério do Desenvolvimento, Indústria e Comércio, da Sociedade Brasileira de Silvicultura e de outras entidades do patronato florestal brasileiro, com apoio da Organização Internacional de Madeiras Tropicais (ITTO) (Garlip, 2002). Para a AIMEX, a criação de um selo brasileiro era vista como uma necessidade para romper com o monopólio do FSC, de forma semelhante a iniciativas de outros países produtores de madeiras tropicais (Boletim semanal..., 2000b).

Assim, podemos dizer que a postura inicial da AIMEX frente à certificação florestal foi dupla: por um lado, criticou fortemente a interferência das ONGs do Norte (o ecolonialismo) nos destinos da Amazônia, promovendo um selo florestal concorrente (o do CERFLOR); por outro lado, defendeu os interesses de seus associados, participando internamente das estruturas do FSC-Brasil.

Com o passar do tempo, a posição da entidade se modificou, o discurso inicial de denúncia do ecolonialismo foi abandonado, passando a dar lugar a uma ação mais ofensiva no que concerne à defesa de medidas de promoção da exploração florestal sustentável e da construção de uma agenda pública de promoção da indústria florestal na Amazônia. Como parte desse novo posicionamento, observamos também uma mudança da AIMEX com relação ao FSC, com a passagem de uma posição negativa e de disputa para uma apreciação mais positiva, como mostra o fato da empresa ter integrado o Conselho Diretor do FSC Brasil, gestão 2001-2003.

Essa mudança de posicionamento pode ser associada a alguns fatores, entre os quais destacamos: o número crescente de empresas filiadas à AIMEX que obtiveram certificação do FSC $^{10}$, caso da Juruá e Cikel em 2001, da Lisboa Madeiras e Exportadora de Madeira do Pará (EMAPA) em 2003; a força que a certificação veio a assumir no mercado internacional de madeiras, tornando-se uma referência incontornável para empresas que querem atingir o mercado europeu e americano, caso das principais empresas representadas pela AIMEX.

Essa mudança em relação à certificação, ou melhor, quanto à agenda de mudanças defendidas para o setor florestal pelos proponentes da certificação, pode ser melhor apreciada se considerarmos que os dois últimos presidentes da AIMEX são oriundos de empresas florestais certificadas (da Cikel Brasil Verde e Juruá Florestal). De forma semelhante, podemos citar o depoimento proferido pelo presidente da AIMEX, por ocasião da VIII Feira de Máquinas, Móveis e Produtos do Setor Madeireiro, realizada entre 28 e 31 de outubro de 2009, em Belém, Pará, sobre a procura por madeiras certificadas como um dos principais resultados do evento:

A madeira com certificação florestal foi um dos itens que obtiveram bastante procura por parte dos visitantes. Conforme o presidente da AIMEX, Idacir Peracchi, essa postura demonstra o crescimento da consciência ecológica do mercado comprador e reafirma a credibilidade do setor florestal no estado do Pará (AIMEX, 2010).

Como destacam os estudos de sociologia econômica, essa mudança de comportamento de empresários, cujas

\footnotetext{
10 Estamos nos referindo somente à certificação da área de manejo florestal. Quando consideramos a certificação da cadeia de custódia (que permite a compra e venda de madeira certificada), o número de empresas associadas à AIMEX que se certificou é bem maior (casos da Brascomp, Laminados do Pará, Nordisk Timber, Eldorado e Tramontina Belém).
} 
atividades se desenvolvem em ambientes marcados por forte contestação social (Hommel, 2004), pode ser compreendida como uma tentativa de internalizar variáveis sociais e ambientais na gestão dos seus negócios (Abramovay, 2009), ao mesmo tempo em que refletem os investimentos realizados por diferentes atores e instituições na mudança da trajetória dessas empresas (Carneiro, 2004; 2007).

\section{A DINÂMICA DO DESENVOLVIMENTO DA CERTIFICAÇÃO FSC NA AMAZÔNIA E SUA ADOÇÃO POR EMPRESAS FLORESTAIS PIONEIRAS}

A implantação do FSC no Brasil se desenrolou paralelamente ao processo internacional. Diversas entidades ambientais e empresariais brasileiras participaram da assembleia de fundação e, no retorno ao país, engajaram-se no movimento de implantação de uma iniciativa nacional - nome que é conferido às seções nacionais do FSC - , o que foi formalizado em setembro de 2001, com a criação do Conselho Brasileiro de Manejo Florestal (outra designação do FSC-Brasil).

O processo de certificação de operações florestais pelo sistema do FSC no Brasil começou nos anos 1990, concentrando-se inicialmente nas regiões Sul e Sudeste, em plantações de pinus e eucalipto de grandes empresas do setor de papel e celulose. Para florestas naturais na Amazônia, a primeira certificação ocorreu em 1997, na unidade de manejo florestal (UMF) da empresa Precious Wood Amazônia (também denominada Mil Madeireira Ltda.), ganhando mais força na década seguinte, com a certificação de empreendimentos comunitários e empresariais.

$\mathrm{Na}$ Tabela 1, apresentamos informações referentes às empresas que tiveram operações de manejo florestal madeireiro certificadas. A partir dela, é possível verificar que, depois de um início tímido, concentrada em empresas tradicionais do setor madeireiro (com exceção da PWA) nos estados do Pará e Amazonas, a certificação tem se diversificado e vem conseguindo atingir empresas situadas nos estados de Rondônia e Mato Grosso, áreas para onde a expansão madeireira se deslocou em período mais recente.

Vale ressaltar também o desenvolvimento recente da certificação de unidades empresariais no Acre, que pode ser apreendido como o resultado da política de fomento ao estabelecimento de uma indústria florestal de qualidade, levada a efeito pelo governo estadual. Por conta desse apoio, tivemos nesse estado a primeira certificação de uma floresta pública no Brasil, a certificação das operações florestais na Floresta Estadual do Antimary (FEA), sob a responsabilidade da Fundação de Tecnologia do Acre (FUNTAC).

Como a madeira extraída na FEA é certificada, as empresas que vencem a licitação" para sua compra possuem a opção de certificar sua cadeia de custódia e, portanto, de vender seu produto com o selo do FSC.

Além da certificação dessa floresta pública, duas empresas tiveram áreas de manejo certificadas, a Laminados Triunfo e a Ouro Verde Importação e Exportação Ltda. Vale ressaltar que as exportações dessas duas empresas certificadas responderam por $52,63 \%$ do valor total das exportações do estado do Acre no ano de $2007^{12}$.

Ainda no caso desse estado, deve ser destacado também o papel do WWF-Brasil que, por meio do programa Sistema de Implantação e Verificação Modular (SIM), vem fornecendo informações para que empresas madeireiras localizadas no Acre possam enfrentar as exigências do processo de certificação do FSC. A certificação por módulos é uma proposta que visa facilitar o acesso de empresas ao processo de certificação, com o argumento de que, dividindo a plena conformidade à norma em uma sucessão de etapas, torna-se possível destinar os recursos empresariais disponíveis para uma ou duas tarefas a cada vez, em lugar de tentar enfrentar todas as atividades necessárias para a certificação (Carneiro, 2004).

\footnotetext{
11 Como essa floresta estadual de produção começou a ser explorada antes da aprovação da Lei de Gestão das Florestas Públicas, a colheita florestal e a venda da madeira para empresas privadas ocorreu através do mecanismo da licitação, conforme a Lei Geral de Licitações (Lei n. 8.666, de 21 de junho de 1993 - Brasil, 1993).

12 Conforme informações coligidas na página eletrônica do Ministério do Desenvolvimento, Indústria e Comércio (Brasil, 2011).
}

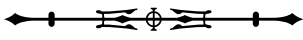


Tabela 1. Identificação, localização, tamanho, ano de certificação e situação atual das unidades de manejo florestal empresarial certificadas na Amazônia brasileira.

\begin{tabular}{|c|c|c|c|c|}
\hline \multirow[b]{2}{*}{ Empresa } & \multirow[b]{2}{*}{ Localização } & \multirow{2}{*}{$\begin{array}{l}\text { Área certificada } \\
\text { (em hectares) }\end{array}$} & \multicolumn{2}{|c|}{ Certificação } \\
\hline & & & $\begin{array}{l}\text { Primeira } \\
\text { certificação }\end{array}$ & $\begin{array}{c}\text { Situação } \\
\text { Atual }\end{array}$ \\
\hline Precious Wood Amazônia (PWA) & Itacoatiara (AM) & $122.700,00$ & 1997 & Válida \\
\hline GETHAL Amazonas & Manicoré (AM) & $40.862,00$ & 2000 & Cancelada \\
\hline Juruá Florestal Ltda. (Fazenda Santa Marta) & Tailândia (PA) & $12.000,00$ & 2001 & Cancelada \\
\hline Cikel Brasil Verde S.A. & Paragominas (PA) & $140.658,00$ & 2001 & Válida \\
\hline Juruá Florestal Ltda. (Fazenda Arataú) & Novo Repartimento (PA) & $30.651,00$ & 2002 & Válida \\
\hline Precious Wood Belém & Portel (PA) & $76.390,00$ & 2003 & Cancelada \\
\hline Guavirá Industrial e Agroflorestal Ltda. & Nova Maringá (MT) & $61.647,44$ & 2003 & Cancelada \\
\hline Exportadora de Madeira do Pará (EMAPA) & Afuá e Chaves (PA) & $12.000,00$ & 2003 & Cancelada \\
\hline Agroflorestal Vale do Guaporé Ltda. & Alta Floresta D'Oeste (RO) & $4.924,00$ & 2003 & Cancelada \\
\hline Rohden Indústria Lígnea Ltda. & Juruena (MT) & $25.100,00$ & 2003 & Recertificação \\
\hline Orsa Florestal & Almeirim/Monte Dourado (PA) & $545.335,00$ & 2004 & Válida \\
\hline Izabel Madeiras do Brasil & Breu Branco (PA) & $20.000,00$ & 2004 & Cancelada \\
\hline Ecolog Indústria e Comércio Ltda. & Porto Velho (RO) & $22.132,00$ & 2004 & Recertificação \\
\hline Cikel Brasil Verde S.A. & Portel (PA) & $123.628,40$ & 2004 & Válida \\
\hline Floresta Estadual do Antimary (FUNTAC) & Bujari (AC) & $47.061,00$ & 2004 & Válida \\
\hline Indústria de Madeiras Manoa Ltda. & Cujubim (RO) & $73.079,00$ & 2005 & Válida \\
\hline Laminados Triunfo Ltda. & Sena Madureira $(A C)$ & $7.873,00$ & 2005 & Válida \\
\hline Ouro Verde Importação e Exportação Ltda. & Bujari (AC) & $14.376,00$ & 2006 & Válida \\
\hline Madeireira Vale Verde & Caracaraí (RR) & $17.205,40$ & 2008 & Válida \\
\hline
\end{tabular}

Fonte: FSC (2010), SCS (2010), IMAFLORA (2010).

Apesar do aumento do número de operações florestais certificadas identificado na Tabela 1, o incremento da certificação de florestas naturais na Amazônia brasileira tem ocorrido em um ritmo bastante lento, fruto dos custos necessários para a passagem de uma exploração florestal tradicional para uma certificada e dos obstáculos existentes para a adoção da Exploração de Impacto Reduzido (Sabogal et al., 2005), que é a tecnologia a ser adotada pelas empresas que pretendem obter a certificação para exploração de florestas naturais na Amazônia.

As informações sobre a evolução da área e do número de operações de manejo florestal empresarial certificados mostram que, no período compreendido entre os anos 2000-
2004, houve um incremento importante no total da área certificada, contudo, a partir de 2005, o ritmo da certificação empresarial declina fortemente (Carneiro, 2009), o que faz com que a área total de manejo florestal empresarial certificada atualmente corresponda a 1.164.147 hectares.

As certificações canceladas apresentadas na Tabela 1 responderam por um total de 227 mil hectares. $O$ cancelamento de um certificado pode ser em decorrência de vários motivos (desistência da empresa, não cumprimento das regras do FSC etc.). Para os casos que possuímos informações, o motivo mais comum foi a insegurança fundiária, a não comprovação do domínio sobre a propriedade fundiária e dificuldades de obtenção da autorização para a

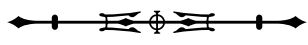


exploração florestal junto ao Instituto Brasileiro do Meio Ambiente e dos Recursos Naturais Renováveis (IBAMA). A dificuldade para obtenção dessa autorização legal (plano anual de exploração) foi particularmente acentuada no ano de 2005, o que levou ao enfraquecimento da feira brasileira de produtos florestais certificados, pois ficaram sem produção para a venda (Mantelatto et al., 2008, p. 298).

Além das dificuldades acima apontadas, essa redução no ritmo de operações certificadas pode ser explicada também pela expectativa gerada entre os empresários do setor florestal pela aprovação da Lei de Gestão das Florestas Públicas (Lei 11.284, de 2 de março de 2006 Brasil, 2006) e do início do processo efetivo de licitação das áreas para exploração das florestas públicas por meio do mecanismo de concessão ${ }^{13}$. Segundo essa perspectiva, a operacionalização da Lei de Gestão das Florestas Públicas (LGFP) permitirá a exploração de recursos madeireiros em terras com a situação jurídica plenamente definida, eliminando o principal obstáculo para a modernização da atuação da indústria florestal na região, conforme desejado pelo empresariado do setor florestal.

Apesar das expectativas geradas pela aprovação da LGFP, a implantação das concessões encontra-se em estágio preliminar, pois, até abril de 2010, o processo de exploração florestal havia iniciado em apenas uma concessão federal, na Floresta Nacional do Jamari (98.350 ha), localizada no estado de Rondônia. Em outra área, na Floresta Nacional de Saraquá-Taquera (140.540 ha), situada no estado Pará, o processo de licitação para exploração dos lotes foi finalizado, enquanto a concessão da Floresta Nacional do Amana (210.161,5 ha), também no Pará, encontra-se em fase de preparação para licitação.

Para termos uma dimensão mais real do volume de madeira que será colocado no mercado a partir da operacionalização da política de concessões, seria necessário considerar também as concessões florestais que estão sendo licitadas nas unidades subnacionais, cujas áreas passíveis de concessão encontram-se em estágios bastante diferenciados e que, segundo os dados do Serviço Florestal Brasileiro (MMA/SFB, 2009b, p. 44-45), corresponderiam a um potencial aproximado de 9,2 milhões de hectares no Pará, 1,3 milhão no Amapá e 154 mil no Acre.

\section{A EVOLUÇÃO DAS EMPRESAS PIONEIRAS}

As primeiras empresas que obtiveram o selo do FSC distinguem-se do conjunto de firmas que integram o campo da produção de madeiras tropicais na Amazônia brasileira. A singularidade dessas empresas pode ser relacionada com sua maior capacidade financeira, a forte dependência do mercado consumidor europeu e as relações privilegiadas com uma rede de organizações (entidades ambientalistas, cooperação internacional etc.) envolvidas no suporte à certificação florestal (Carneiro, 2007).

A evolução dessas empresas certificadas apresenta detalhes interessantes que mostram os benefícios do acesso à certificação, bem como os obstáculos para a realização do manejo florestal na Amazônia. Das quatro empresas pioneiras que tiveram suas florestas certificadas (Grupo Precious Wood, Gethal Amazonas S/A, Cikel Brasil Verde S/A e Juruá Florestal Ltda.), três continuam em operação, duas das quais (Cikel e Precious Wood Amazônia) vêm ampliando progressivamente sua presença na indústria madeireira regional.

O grupo Precious Wood, que detém a primeira operação de manejo florestal certificada na Amazônia (Fazenda Mil Madeireira, em 1997), obteve sua recertificação em 2005, ampliando-a para 122 mil hectares. Em 2002, o grupo adquiriu uma área no estado do Pará (de 45.738

\footnotetext{
13 A concessão florestal é uma modalidade de contrato por meio do qual um usuário privado recebe o direito de exploração do recurso florestal em terras de domínio público em troca do pagamento de uma taxa pelo aproveitamento desse recurso. Para uma discussão sobre os diversos tipos de taxas passíveis de serem aplicadas à exploração florestal, ver Karsenty (2002). Vale dizer que a proposta de estabelecimento de concessões florestais em áreas públicas não é nova, tendo sido formulada nos anos 1980 por consultores da Food and Agriculture Organization (FAO), sob a rubrica do Contrato de Utilização Florestal (Schmithüsen, 1978, p. 12).
}

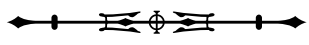


hectares) em nome da empresa Precious Wood Belém, que também foi certificada. Contudo, por força de questionamentos quanto à legalidade da situação fundiária, essa área teve a certificação cancelada e a empresa encerrou suas atividades de processamento da madeira no estado do Pará (Precious Wood, 2009).

Apesar desse revés, a expansão do grupo na região continuou com a ampliação de sua propriedade localizada no estado do Amazonas para 473 mil hectares. No plano internacional, a empresa reforçou sua presença na África, com a aquisição da Compagnie Equatoriale des Bois, no Gabão, que controla uma concessão florestal de 600 mil hectares (Precious Wood, 2009).

A empresa Cikel Brasil Verde é o principal grupo madeireiro certificado na Amazônia. Em 2004, a empresa possuía seis unidades industriais: três serrarias, uma laminadora, uma fábrica de pisos e uma indústria de compensados e laminados. Para abastecer esse conjunto industrial, a empresa possui cerca de 500 mil hectares de florestas, dos quais 206 mil de áreas próprias, localizadas no município de Paragominas (PA) e mais 300 mil hectares arrendados de outras empresas (Almeida, 2003).

Em 2004, a empresa obteve a certificação de sua segunda área de manejo florestal, localizada no município de Portel (PA), possuindo, atualmente, cerca de 264 mil hectares de florestas certificadas na Amazônia. A ampliação da empresa tem ocorrido também para outros segmentos econômicos. Em 2008, a Cikel comprou uma unidade de produção siderúrgica no município de Marabá e passou a produzir também ferro-gusa.

A empresa Juruá Florestal Ltda. mantém uma de suas operações certificadas (Fazenda Arataú), mas perdeu a certificação da Fazenda Santa Marta, localizada no município de Tailândia (PA), por conta de dificuldades na manutenção da integridade do domínio sobre a propriedade da terra, que foi ocupada por extratores ilegais de madeira. Em
2009, a empresa iniciou a exploração de outra área, localizada no município de Almeirim (PA), para a qual não obteve a certificação do FSC, apesar de notícias divulgadas nesse sentido pela imprensa regional.

Das empresas que classificamos como pioneiras, somente a Gethal Amazônia não existe mais, devido às dificuldades enfrentadas em manter suas operações florestais e à decisão do seu proprietário (o fundo de investimentos Brazilian Forestry Fund Investments) em sair da atividade florestal. Em 2005, ela perdeu a certificação por conta de obstáculos enfrentados com a obtenção da autorização para a realização do manejo florestal junto ao IBAMA. No ano de 2006, a empresa foi vendida para um empresário europeu (J. Eliasch), que decidiu suspender a atividade de manejo florestal na área certificada da empresa.

Esse rápido balanço da situação das empresas pioneiras, assim como a observação das empresas certificadas em período mais recente (Carneiro, 2009), mostra que a adoção da certificação do FSC continua fortemente dependente da capacidade dessas empresas demonstrarem que possuem acesso legal não contestado ao recurso florestal, isto é, o domínio inconteste sobre a terra em que suas atividades estão implantadas. Esse aspecto, que os empresários do setor esperam ver superado com a implantação das concessões florestais, favoreceu, por exemplo, a certificação das empresas Orsa Florestal $S / A^{14}$, Laminados Triunfo e Ouro Verde Exportação e Importação, que se implantaram no estado do Acre.

Por conseguinte, podemos dizer que, apesar de todo o investimento realizado para o suporte ao desenvolvimento da certificação de florestas manejadas na Amazônia, o número de empresas certificadas continua muito reduzido. Como já ressaltamos (Carneiro, 2007), essas empresas formam um oligopólio face às milhares de médias e pequenas empresas que compõem o setor madeireiro regional (Lentini et al., 2005), o que fortalece

\footnotetext{
14 No ano 2000, o grupo Orsa assumiu os negócios e as terras da empresa Jari Celulose, que possuía uma área de 1.700 hectares nos estados do Pará e Amapá. Dentro dessa área, o grupo mantém atividades de exploração florestal com plantios homogêneos (realizada pela empresa Jari Celulose) e por meio de manejo florestal (realizada pela empresa Orsa Florestal).
}

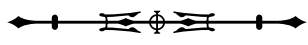


os temores de que a política de concessões possa vir a favorecer essa concentração (Guéneau, 2006) ou que leve ao domínio de grupos florestais internacionais sobre as áreas que serão licitadas (Merry et al., 2003, p. 8).

Para responder a esse tipo de crítica, a Lei de Gestão das Florestas Públicas estabeleceu alguns mecanismos a fim de evitar a concentração econômica das concessões, caso do artigo n. 3, o qual estabelece a obrigação da licitação de lotes de tamanhos diferentes (para atender "pessoas jurídicas de pequeno porte, micro e médias empresas"), e do artigo n. 77, que estabelece um limite máximo (dez por cento) de áreas de concessão possíveis de serem detidas por um único proprietário.

\section{CONSIDERAÇÕES FINAIS: A CERTIFICAÇÃO COMO CATALISADORA DE MUDANÇAS NA EXPLORAÇÃO FLORESTAL NA AMAZÔNIA}

Uma leitura apressada dos dados apresentados na seção anterior poderia levar à conclusão de que houve fracasso da certificação florestal na Amazônia, uma vez que o volume de madeira certificada não ultrapassa 3\% da produção de madeira (IMAFLORA, 2005, p. 73) e que o número de empresas certificadas permanece bastante limitado.

Contudo, como anunciamos na introdução, sustentamos outra interpretação sobre o significado da promoção do selo do FSC na Amazônia. Destarte, a tese que defendemos é que os principais resultados associados à promoção da certificação na Amazônia estão relacionados: i) com a formação de uma aliança entre setores do empresariado florestal, das ONGs ambientalistas e de parcela da burocracia estatal relacionada com a gestão ambiental brasileira; e ii) com a efetivação de mudanças importantes no quadro institucional, que servem de base para o funcionamento da indústria madeireira na Amazônia.

Pensamos que a certificação operou de duas formas para a promoção dessa aliança: por meio da construção de vínculos entre membros desses três grupos sociais (empresários, ONGs e burocracia estatal) e da promoção política e econômica ${ }^{15}$ das empresas pioneiras na adoção do certificado do FSC.

Nesse primeiro caso, podemos destacar o papel desempenhado pelas diversas atividades realizadas no âmbito das ações de promoção da certificação (workshops, elaboração de estudos, realização de feiras), bem como a circulação de defensores da certificação em posições nas ONGs, na burocracia estatal e nas empresas certificadas. A título de ilustração, podemos citar o depoimento de Tasso Azevedo, ex-secretário executivo do IMAFLORA, que, numa edição comemorativa da história da certificação florestal no Brasil, relatou:

Em 2003 fui trabalhar na Diretoria do Programa Nacional de Florestas do Ministério do Meio Ambiente e toda essa experiência (do trabalho na promoção da certificação) tem servido de inspiração para promover as grandes mudanças necessárias para criar um ambiente institucional propício à promoção da conservação e do manejo às florestas no Brasil (IMAFLORA, 2005, p. 26).

Como exemplo da promoção política dos empresários 'verdes' do setor madeireiro regional, podemos citar o fato que os dois últimos presidentes da AIMEX, principal entidade de representação das empresas florestais na Amazônia brasileira, são empresários das primeiras empresas certificadas no estado do Pará (Cikel Brasil Verde e Juruá Florestal), refletindo uma mudança importante na composição da direção dessa entidade, que, durante muito tempo, preconizou uma oposição à proposta da certificação.

No que concerne às mudanças no quadro institucional, a atuação dos defensores da certificação desempenhou um papel importante na formulação e na defesa daquela que pode ser considerada como a principal

\footnotetext{
15 Por meio do acesso a nichos de mercado, da obtenção de preços melhores, de benefícios indiretos (treinamento da mão de obra) e do marketing verde.
}

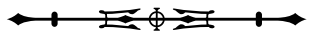


política para a viabilização da exploração baseada no manejo florestal na Amazônia: a LGFP. Outro efeito que deve ser mencionado refere-se à sua influência na criação e estruturação de órgãos para o fomento da atividade florestal na Amazônia (SFB, IDEFLOR), ou seja, em dois dos principais entraves (segurança fundiária, fomento à produção) para a promoção do manejo florestal.

A apresentação da proposta da LGFP sofreu diversos tipos de crítica. No plano mais geral, foi difundida a ideia de que ela promoveria a privatização das terras públicas na Amazônia, privilegiando a atuação de grandes empresas internacionais. No front específico da discussão (ou batalha) dos experts florestais, os argumentos principais incidiam na inviabilidade ecológica ou financeira da proposta (Merry et al., 2003) ou na fragilidade do Estado para realizar o monitoramento do manejo e da exploração florestal nas concessões (Nepstad et al., 2005).

A principal resposta a essas críticas veio de experts florestais do IMAZON, que, tendo participado dos estudos preliminares (Barreto e Arima, 2002) para a elaboração da proposta da LGFP, encontravam-se bem posicionados para realizar sua defesa. Segundo esse ponto de vista, a exploração florestal em áreas públicas (nas Florestas Nacionais - FLONAS) seria a única opção de atender à demanda sustentável ${ }^{16}$ por madeira da indústria amazônica, e os mecanismos de gestão da LGFP garantiriam seu caráter democrático, bem como evitariam a concentração econômica (Veríssimo e Cochrane, 2003, p. 5-6).

Além dessa defesa, podemos identificar na LGFP e nos procedimentos de licitação das concessões florestais pelo menos dois elementos diretamente inspirados na certificação: a realização da Auditoria Florestal (AF) e a construção de um caderno de indicadores para o julgamento das melhores propostas de exploração das Concessões. Segundo a legislação que normatiza o processo de monitoramento da exploração das concessões ${ }^{17}$, as auditorias farão parte das ações de fiscalização das Concessões, que deverão ser realizadas em três níveis: pelo Instituto Chico Mendes de Conservação da Biodiversidade (ICMBio), pelo próprio SFB e por empresas a serem contratadas para a realização da auditoria independente.

O processo de estruturação da AF é bastante semelhante ao procedimento de certificação pelo FSC, que se baseia na ideia da avaliação da atividade florestal por uma terceira parte, sem envolvimento direto. No caso das concessões federais, foi elaborada uma norma que servirá de guia para as auditorias e o Instituto Nacional de Metrologia, Normalização e Qualidade Industrial (INMETRO), e cumprirá o papel de órgão de credenciamento das empresas aptas a realizarem a auditoria (MMA/SFB, 2009a, p. 36).

Essa correspondência, identificada entre procedimentos de certificação e os mecanismos de operacionalização da política de concessões, não significa que esta é o produto direto daquela. Além de estudos preliminares sobre outras experiências de concessões no mundo, o projeto de lei foi objeto de discussões com a sociedade civil (audiências públicas) e de debate parlamentar.

Quando relacionamos a política de concessões com a certificação, o que queremos ressaltar é o papel desempenhado por esta última, como uma espécie de 'laboratório' para o desenvolvimento das práticas de manejo florestal (a exploração de impacto reduzido), que serão sancionadas pelos mecanismos de seleção das empresas aptas para a exploração das florestas públicas de produção. Por outro lado, a certificação também teve o efeito de possibilitar o desenvolvimento de empresas florestais 'vencedoras', isto é, capazes de realizar o manejo florestal, obtendo resultados econômicos satisfatórios, além de possibilitar a construção de um amplo movimento de apoio à difusão do manejo florestal como alternativa efetiva de desenvolvimento na Amazônia brasileira.

\footnotetext{
16 Sustentabilidade, aqui, tem um duplo sentido, referindo-se tanto ao abastecimento regular de matéria-prima florestal quanto ao fato de que a madeira obtida nas concessões é de origem legal e explorada sob os princípios da EIR.

17 Conforme Seção XII da Lei n. 11.284 (Brasil, 2006) e o Capítulo VIII do Decreto n. 6.063, de 20 de março de 2007 (Brasil, 2007).
}

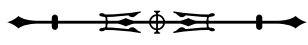


Um último ponto a ser destacado é que, de forma aparentemente paradoxal, o sucesso da política de concessões florestais pode representar o fim do mercado da certificação na Amazônia, tal como este tem funcionado até o presente momento. A hipótese que avançamos está relacionada com a perspectiva de que a política de concessões florestais consiga cumprir sua promessa de possibilitar o acesso seguro ao recurso florestal para as empresas madeireiras e que tenha êxito na construção dos mecanismos de monitoramento previstos, por meio do SFB, do ICMBio e da Auditoria Florestal Independente (regulada pelo INMETRO).

Nesse caso, teríamos uma situação na qual o acesso às concessões florestais funcionariam por si só como um certificado de boas condutas sociais e ambientais, permitindo o acesso das empresas florestais concessionárias aos mercados de produtos florestais mais exigentes (europeu e norte-americano), ficando a certificação como uma opção para aquelas situações (hoje bastante excepcionais) em que as empresas possuem acesso ao recurso florestal de forma inconteste, em uma dimensão suficiente para a garantia de sua reprodução econômica.

Outra possibilidade é que haja um movimento de reconhecimento da Auditoria Florestal Independente como um selo florestal pelo FSC-Brasil e pelo CERFLOR, de forma semelhante ao que ocorre com a proposição do reconhecimento mútuo entre diferentes selos florestais existentes (Smouts, 2001; Fern, 2001; Carneiro, 2004). Nesse caso, a avaliação feita no sistema de concessão teria que ser equiparada aos princípios e critérios desses dois sistemas de certificação, diminuindo os gastos que uma empresa concessionária possa vir a ter, caso pretenda obter o selo florestal do FSC ou do CERFLOR.

Em qualquer dessas duas situações, o desfecho é claro: o futuro da indústria florestal na Amazônia passa pela efetivação da política de concessões. Nesse novo contexto, o futuro da certificação florestal é incerto, mas, se quiser sobreviver, ela terá de ser remodelada, de forma a conseguir integrar o dispositivo de monitoramento da exploração florestal nas concessões públicas.

\section{REFERÊNCIAS}

ABRAMOVAY, Ricardo. Responsabilidade socioambiental: as empresas no meio ambiente, o meio ambiente nas empresas. In: VEIGA, J. E. (Org.). Economia socioambiental. São Paulo: SENAC, 2009. p. 335-356.

ALMEIDA, Alcir R. C. Manejo sustentável de florestas nativas: o caso da Cikel Brasil Verde S/A. In: SEMINÁRIO A QUESTÃO FLORESTAL E O DESENVOLVIMENTO, 1., 2003, Rio de Janeiro. Anais... Rio de Janeiro: BNDES, 2003.

AMIGOS DA TERRA. Programa Amazônia. Garimpagem Florestal: Relatório atualizado sobre a extração ilegal de madeira na Amazônia brasileira. São Paulo, 1997. 77 p.

ASSOCIAÇÃO DAS INDÚSTRIAS EXPORTADORAS DE MADEIRA DO ESTÁDO DO PARÁ (AIMEX). Disponível em: <http:// www.inteligentesite.com.br/modelos/modelo57/subconteudo. asp?ID =432\&IDSUBLINK=5011>. Acesso em: 5 maio 2010.

BARRETO, Paulo; ARIMA, Eugênio. Florestas nacionais na Amazônia: consultas a empresários madeireiros e atores afins à política florestal. Brasília: Ministério do Meio Ambiente, 2002.

BENCHIMOL, Samuel. Exportação da Amazônia brasileira - 1997. Manaus: Editora Valer, 1998.

BOLETIM SEMANAL [da] Associação das Indústrias Exportadoras de Madeira do Estado do Pará. Belém, n. 2, 2000a. 2 p.

BOLETIM SEMANAL [da] Associação das Indústrias Exportadoras de Madeira do Estado do Pará. Belém, n. 2, 2000b. 2 p.

BOLETIM SEMANAL [da] Associação das Indústrias Exportadoras de Madeira do Estado do Pará. Belém, n. 2, 1998. 2 p.

BRASIL. Ministério do Desenvolvimento, Indústria e Comércio. Balança comercial por Unidade da Federação. 2011. Disponível em: <http://www.desenvolvimento.gov.br/sitio/interna/interna.ph p?area $=5 \&$ menu $=1078 \&$ refr $=1076>$. Acesso em: 12 fev. 2011.

BRASIL. Decreto n. 6.063, de 20 de março de 2007. Regulamenta, no âmbito federal, dispositivos da Lei no 11.284, de 2 de março de 2006, que dispõe sobre a gestão de florestas públicas para a produção sustentável, e dá outras providências. Diário Oficial, Brasilia, Distrito Federal, 20 mar. 2007. Disponível em: <http://unw.planalto.gov.br/ccivil 03/Ato20072010/2007/Decreto/D6063.htm >. Acesso em: 3 fev. 2010.

BRASIL. Lei n. 11.284, de 2 de março de 2006. Dispõe sobre a gestão de florestas públicas para a produção sustentável; institui, na estrutura do Ministério do Meio Ambiente, o Serviço Florestal Brasileiro - SFB; cria o Fundo Nacional de Desenvolvimento Florestal - FNDF; altera as Leis nos 10.683, de 28 de maio de 2003, 5.868, de 12 de dezembro de $1972,9.605$, de 12 de fevereiro de 1998, 4.771, de 15 de setembro de 1965, 6.938, de 31 de agosto de 1981, e 6.015, de 31 de dezembro de 1973; e dá outras providências. Diário Oficial, Brasília, Distrito Federal, 2 mar. 2006. Disponível em: < http://mww.planalto.gov.br/ccivil_03/ Ato2004-2006/2006/Lei/L11284.htm > . Acesso em: 3 fev. 2010.

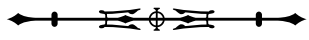


BRASIL. Lei n. 8.666, de 21 de junho de 1993. Regulamenta o art. 37, inciso XXI, da Constituição Federal, institui normas para licitações e contratos da Administração Pública e dá outras providências. Diário Oficial, Brasília, Distrito Federal, 22 jun. 1993. Disponível em: <http://www.planalto.gov.br/ccivil_03/leis/L8666cons.htm>. Acesso em: 3 fev. 2010

BUCLET, Benjamin. Les expérimentations des ONGs en Amazonie: quel pouvoir pour quelle responsabilité? Lusotopie, n. 1, p. 263282, 2002.

BULL, G. Q.; PULKKI, R.; KILLMANN, W.; SCHWAB, O. Exploitation coûteuse ou rentable? Actualités des Forêts Tropicales, v. 9, n. 2, p. 12-13, 2001.

CARNEIRO, Marcelo S. O desenvolvimento da certificação sócio-ambiental e a nova dinâmica da ação empresarial na Amazônia. In: FERRETTI, S.; RAMALHO, J. R. (Orgs.). Amazônia: desenvolvimento, meio ambiente e diversidade sociocultural São Luís: Editora da UFMA, 2009. p. 17-44.

CARNEIRO, Marcelo S. A construção social do mercado de madeiras certificadas na Amazônia brasileira: a atuação das ONGs ambientalistas e das empresas pioneiras. Sociedade e Estado, v. 22, n. 3, p. 681-713, 2007.

CARNEIRO, Marcelo S. O dinheiro é verde? A construção social do mercado de madeiras certificadas na Amazônia brasileira. 2004. $251 \mathrm{f}$. Tese (Doutorado em Sociologia) - Universidade Federal do Rio de Janeiro, Rio de Janeiro, 2004.

COSTA, Francisco de Assis. A questão agrária na Amazônia e os desafios estratégicos de um novo desenvolvimento. In: BECKER, B.; ALVES, D.; COSTA, W. M. (Orgs.). Dimensões humanas da biosfera-atmosfera na Amazônia. São Paulo: EDUSP, 2007. p. 129-166.

COUTO, Suelene; RONCOLETTA, Maximiliano. Capacitação e treinamento: um caminho para a preservação das florestas. In: BENSUSAN, N.; ARMSTRONG, G. (Orgs.). O manejo da paisagem e a paisagem do manejo. Brasília: Instituto Internacional de Educação do Brasil, 2008. p. 215-228.

DYKSTRA, Dennis P. L'exploitation à faible impact: l'ancien et le nouveau. Actualités des Forêts Tropicales, v. 9, n. 2, p. 3-4, 2001.

FAILLACE, Sandra. A quem interessa o FSC? In: LEROY, J. P.; FATHEUER, T. W. (Orgs.). Certificação Florestal. Rio de Janeiro: FASE, 1996. p. 17-25.

FERN. Derrière le label: une évaluation des programmes de certification des forêts du point de vue écologique et social. 2001. Disponível em: <http://www.aves.asso.fr/junior/IMG/pdf/ fern_ecocertification.pdf >. Acesso em: 15 fev. 2010.

FOREST STEWARDSHIP COUNCIL (FSC). FSC Certificate Database. 2010. Disponível em : <info.fsc.org./ publicCertificateSearch>. Acesso em: 6 fev. 2010.
FUNDAÇÃO FLORESTA TROPICAL (FFT). Relatório das atividades da Fundação Floresta Tropical no ano de 2000. Belém: FFT, 2001.

FUNDAÇÃO FLORESTA TROPICAL (FFT). Atuação da Fundação Floresta Tropical no manejo sustentável da floresta amazônica (1994-1999). Belém: FFT, 2000

GARLIP, Rubens. CERFLOR: Sistema Brasileiro de Certificação Florestal. In: CONFERÊNCIA INTERNACIONAL SOBRE MADEIRAS TROPICAIS, 1., 2002, Belém. Anais... Belém: ITTO/ SINDIMADE, 2002. p. 54-63.

GREENPEACE BRASIL. Campanha Amazônia. Estado de conflito: uma investigação sobre grileiros, madeireiros e fronteiras sem lei do estado do Pará, na Amazônia. 2003. Disponível em: < http:// www.greenpeace.org.br/amazonia/pdf/para estadodeconflito.pdf $>$. Acesso em: 15 fev. 2004.

GREENPEACE BRASIL. Cerflor - empresas e governo têm credibilidade para realizar certificação florestal? 2002. Disponível em: <http://www.ciflorestas.com.br/arquivos/doc certificacao florestal 640.pdf >. Acesso em: 15 fev. 2004.

GREENPEACE INTERNATIONAL. Alternatives commerciales à la destruction des forêts anciennes. Amsterdam, 1999a. Disponível em: <http://dl.deforestation-amazonie.org/rapp_2.pdf>. Acesso em: 15 fev. 2004.

GREENPEACE INTERNATIONAL. Le visage de la destruction: un rapport de Greenpeace sur l'industrie du Bois en Amazonie Brésilienne. Amsterdam, 1999b. Disponível em: < http://dl.deforestationamazonie.org/rapp_1.pdf>. Acesso em: 15 fev. 2004.

GUÉNEAU, Stéphane. La certification de la gestion forestiére au Brésil: portée et limites des nouvelles formes de gouvernance privées. In: CONGRES INTERNATIONAL DES AMERICANISTES, 52., 2006, Sérville. Anais... Sérville: IDDRI, 2006. Disponível em: $<$ http://www.iddri.org/Activites/Interventions/070613 gueneau certificationforestierebres conflCA.pdf > . Acesso em: $1 \overline{5}$ fev. 2010.

HINRICHS, A.; RUSLIM, Y. Mise en oeuvre de l'EFI en Indonésie. Actualités des Forêts Tropicales, v. 9, n. 2, p. 6-7, 2001.

HIRSCHMAN, Albert O. Saída, voz e lealdade: reações ao declínio de firmas, organizações e estados. São Paulo: Perspectiva, 1973.

HOMMEL, Thierry. Stratégies des firmes industrielles et contestation sociale. Paris: CEMAGREF/CIRAD/IFREMER/INRA, 2004.

INSTITUTO DE MANEJO E CERTIFICAÇÃO FLORESTAL E AGRÍCOLA (IMAFLORA). Produtos e empreendimentos certificados. Banco de Dados. 2010. Disponível em: < www.imaflora. org/index.php/empreendimento/ista/tudo > . Acesso em: 6 fev. 2010.

INSTITUTO DE MANEJO E CERTIFICAÇÃO FLORESTAL E AGRÍCOLA (IMAFLORA). Brasil certificado: a história da certificação florestal no Brasil. Piracicaba: IMAFLORA, 2005. 
INSTITUTO DE MANEJO E CERTIFICAÇÃO FLORESTAL E AGRíCOLA (IMAFLORA). Relatório Anual. Plano estratégico IMAFLORA 1998/2000 Fundação Ford. Piracicaba, 2000.

KARSENTY, Alain. Fiscalité et gestion des forêts tropicales. Cahiers d'Economie et Sociologie Rurales, n. 64, p. 6-36, 2002.

LASCHEFSKI, Klemens. Políticas públicas para um desenvolvimento sustentável na Amazônia. O papel da "vocação florestal". Boletim Rede Amazônia, ano 2, n. 1, p. 83-95, 2003.

LENTINI, M.; PEREIRA, D.; CELENTANO, D.; PEREIRA, R. Fatos florestais da Amazônia 2005. Belém: IMAZON, 2005. Disponível em: <http://www.amazonia.org.br/arquivos/189125.pdf>. Acesso em: 16 fev. 2010.

LIMA, A. C. B.; KEPPE, A. L. N.; MAULE, F. E.; SPAVOREK, G.; ALVES, M. C.; MAULE, R. F. E certificar, faz diferença? Estudo de avaliação do impacto da certificação FSC/RAS. Piracicaba: IMAFLORA, 2009.

MANTELATTO, P.; ARANTES, A.; FREITAS, A. A Feira do Brasil Certificado. In: BENSUSAN, N.; ARMSTRONG, G. (Orgs.). O manejo da paisagem e a paisagem do manejo. Brasília: Instituto Internacional de Educação do Brasil, 2008. p. 295-299.

MERRY, F. D.; AMACHER, G. S.; POKORNY, B.; LIMA, E.; SCHOLZ, I.; NEPSTAD, D.; ZWEEDE, J. C. De doutes au sujet des concessions au Brésil. Actualités des Forêts Tropicales, v. 11, n. 3, p. 7-9, 2003.

MINISTÉRIO DO MEIO AMBIENTE/SERVIÇO FLORESTAL BRASILEIRO (MMA/SFB). Gestão de florestas públicas-Relatório 2008. Brasilia: Ministério do Meio Ambiente/Senviço Florestal Brasileiro, 2009a.

MINISTÉRIO DO MEIO AMBIENTE/SERVIÇO FLORESTAL BRASILEIRO (MMA/SFB). Plano anual de outorga florestal - 2010. Brasilia: Ministério do Meio Ambiente/Serviço Florestal Brasileiro, $2009 \mathrm{~b}$.

NEPSTAD, D.; ALENCAR, A.; BARROS, A. C.; LIMA, E.; MENDONZA, E.; RAMOS, C. A.; LEFEBVRE, P. Governando a indústria madeireira na Amazônia. In: ZARIN, D. J.; ALAVALAPATI, J.; PUTZ, F;; SCHMINK, M. (Orgs.). As florestas produtivas nos neotrópicos. Conservação por meio do manejo sustentável? São Paulo/Brasília: Peirópolis/IEB, 2005. p. 481-511.

PEREIRA, D.; SANTOS, D.; VEDOVETO, M.; GUIMARAES, J.; VERÍSSIMO, A. Fatos florestais da Amazônia - 2010. Belém: IMAZON, 2010.

PRECIOUS WOOD. Annual Report 2008. Zurich, 2009. Disponível em: <http://www.preciouswoods.com/images/ stories/2009/pw_annual_report_08.pdf > . Acesso em: 16 fev. 2010.
SABOGAL, C.; LENTINI, M.; POKORNY, B.; SILVA, J. N. M.; ZWEEDE, J.; VERÍSSIMO, A.; BOSCOLO, M. Manejo florestal empresarial na Amazônia brasileira. Restrições e oportunidades para a adoção de boas práticas de manejo. Belém: CIFOR, 2005. Disponível em: <http://bommanejo.cpatu.embrapa.br/ arquivos/15.1-Sabogaletal2005.pdf>. Acesso em: 16 fev. 2010.

SCHMITHÜSEN, F. Contratos de utilização florestal com referência especial à Amazônia brasileira. Brasília: IBDF/PNUD/ FAO/MINAGRI, 1978.

SCIENTIFIC CERTIFICATIONSYSTEMS(SCS). Forest Conservation Program Certified Clients. 2010. Disponível em: <www. scscertified.com/nac/forest_certclients.php\#southamerica>. Acesso em: 6 fev. 2010.

SEMBER, N. B. G. A indústria madeireira no Pará: estratégias empresariais no uso dos recursos florestais. 1999. 134p. Dissertação (Mestrado em Planejamento do Desenvolvimento) - Universidade Federal do Pará, Belém, 1999.

SILVA, J. N. M.; LOPES, J. C. A.; BARROS, P. C. Aspectos técnicos relacionados aos projetos de manejo florestal na microrregião de Paragominas. In: SEMINARIO SOBRE DIAGNÓSTICO DOS PROJETOSDE MANEJO FLORESTAL NO ESTADO DO PARÁ-FASE PARAGOMINAS, 1., 1996, Belém. Anais... Paragominas: EMBRAPA IBAMA/FCAP/SECTAM/SUDAM/UFPA/FIEPA, 1996. p. 27-41.

SMERALDI, Roberto; VERÍSSIMO, Adalberto. Acertando o alvo: consumo de madeira no mercado interno e promoção da certificação florestal. São Paulo: Amigos da Terra; Piracicaba: IMAFLORA; Belém: IMAZON, 1999.

SMOUTS, Marie-Claude. Forêts tropicales, jungle internationale: le revers de l'ecopolitique mondiale. Paris: Presses de Sciences Po., 2001.

SOBRAL, L.; VERÍSSIMO, A.; LIMA, E.; AZEVEDO, T.; SMERALDI, R. Acertando o alvo 2: consumo de madeira amazônica e certificação florestal no estado de São Paulo. Belém: IMAZON, 2002.

THORNBER, K.; PLOUVIER, D.; BASS, S. L'accès difficile aux avantages de la certification. Discussion des incidences sur l'équité. Joensuu: European Forest Institute, 2000. (Document de discussion, n. 8).

VERÍSSIMO, Adalberto; COCHRANE, Mark A. Une initiative audacieuse em l'amazonie bresilienne. Actualités des Forêts Tropicales, v. 11, n. 3, p. 4-6, 2003.

WORLDWILDLIFE FUND-BRASIL (MWF-Brasil). Desenvolvimento e conservação do meio ambiente: pesquisa de opinião com lideranças e a população da Amazônia. Brasília: WWF-Brasil, 2001.

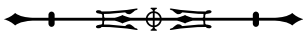

